\title{
Informação de interesse para deficientes visuais e profissionais da informação: procedimentos estratégicos e proposta ao Portal LTi
}

\author{
Ana Sara Pereira de Melo Sobral ${ }^{1}$, Isa Maria Freire ${ }^{2}$ \\ ${ }^{1}$ https://orcid.org/0000-0002-8794-0905 + Instituto Federal Baiano, Bahia, Brasil. \\ anasarap@hotmail.com. \\ ${ }^{2}$ https://orcid.org/0000-0001-7603-1872 + Universidade Federal da Paraíba, Paraíba, Brasil. \\ isafreire@globo.com.
}

\section{RESUMO}

Este estudo propõe ao Portal LTi a publicação de uma página com informações para pessoas deficientes visuais e/ou de interesse para profissionais da informação. Para isto, identificou-se na web fontes de informação para esses grupos, categorizou-se, nas fontes encontradas, produtos e serviços oferecidos, elaborou-se uma proposta ao Portal Virtual do Projeto LTi para disponibilização de informações sobre a temática "deficiência visual". A investigação se caracteriza pelo método indiciário, as técnicas e instrumentos de coletas de dados incluíram o brauseio e uso de planilhas para registro de informações. Dentre os itens encontrados estão: artigos; comunicações; dissertações; ampliadores de tela para usuários com baixa visão; avaliadores de acessibilidade; leitores de tela; sites de audiodescrição; software de síntese e reconhecimento de voz; leis e decretos; página do governo federal acessível; sites de distribuição gratuita de livros em Braille, falados e digitais; blogs; rede social - Facebook e jogos. A pesquisa foi executada com êxito, abrindo possibilidades de criação de uma página denominada LTi $\boldsymbol{D} \boldsymbol{V}$ que reúne informações sobre a temática, tendo como expectativa a constante atualização dos conteúdos, divulgação de novas comunicações, criações e aperfeiçoamento de tecnologia assistiva, bem como 0 acesso a informação, para maior igualdade de oportunidades.

Palavras-chave: Deficientes visuais. Fonte de informação - internet. Método indiciário. Laboratório de Tecnologias Intelectuais (LTi).

\section{Introdução}

O que instigou esse artigo, resultado de dissertação de mestrado, foi à necessidade de procedimentos metodológicos e estratégias de busca para seleção, criação e sistematização de pesquisas em Ciência da informação (CI) sobre a temática "deficiência visual". Assim pretende-se compartilhar tais estratégias de mapeamento de fontes de informações, enfatizando a produção sobre a temática indexada na Base de Dados Referencial de Artigos de Periódicos em Ciência da Informação (Brapci), na Web of Science (WoS), Encontro Nacional de Pesquisa em Ciência da Informação (Enancib), Biblioteca Digital de Teses e Dissertações (BDTD) e conteúdos da internet acerca de blogs, ampliadores de tela, leitores de voz, sites de audiodescrição, avaliadores de acessibilidade, software de síntese e reconhecimento de voz, leis e decretos, páginas do governo federal, serviços e produtos, páginas de livros gratuitos, facebook e Jogos.

O projeto tem como objetivo geral propor ao Portal LTi a publicação de uma página com informações para pessoas deficientes visuais e/ou profissionais da informação. Nomeiam-se os seguintes objetivos específicos:

a) Identificar, na web, fontes de informação direcionadas à pessoa com deficiência visual e/ou 
de interesse para profissionais da informação;

b) Categorizar, nessas fontes, produtos e serviços oferecidos;

c) Elaborar uma proposta ao Portal Virtual do Projeto LTi;

Tendo como intuito disponibilizar informações encontradas sobre a temática no Portal $\mathrm{LTi}^{1}$, o mesmo é constituído por ação de atores sociais que atuam no ensino, pesquisa e extensão do ensino médio, dos cursos de graduação, pós-graduação em CI da UFPB e parceiros de áreas afins. O Portal possui características fundadas com base na troca, compartilhamento, produção do conhecimento e participação da comunidade numa ação coletiva. Assim é direcionado ao setor científico e tecnológico de produção social e cultural, particularmente à comunidade acadêmica e aos profissionais da informação, cultura e informação são interligadas e comunicadas pelos sujeitos. Desse modo, representa, também, a oportunidade para os pesquisadores proponentes tecerem, no tear da CI, um padrão que entrelace informação e tecnologias intelectuais na prática acadêmica.

Além do mais, reconhecemos que essa pesquisa dialoga com o plano de ação da Agenda 2030 para o desenvolvimento sustentável que foi elaborado em 2015 por representantes de vários países, onde foi formulada uma lista com 17 ações a serem cumpridas até 2030. Neste trabalho observaremos o objetivo número 10 que trata da redução das desigualdades e engloba a promoção da inclusão social da pessoa com deficiência, enfatizando a igualdade de oportunidades para todos.

\section{A RESPONSABILIDADE SOCIAL DA CIÊNCIA DA INFORMAÇÃO: a inserção dos indivíduos na sociedade informacional}

Na sociedade do conhecimento todos devem ter acesso à informação que lhes é de direito irrestritamente, e tal fato está intrinsecamente relacionado ao aspecto tecnológico, quesito proeminente em grande parte das atividades da humanidade, sejam técnicas, sejam intelectuais. As tecnologias são desenvolvidas e utilizadas segundo uma lógica ambígua, em que uns possuem o acesso e a competência para a sua utilização, alcançando desenvolvimento pessoal, econômico, cultural, e outros são excluídos, seja pela ausência de aptidões, seja pela dificuldade de acesso, ou por quaisquer questões que ocorrem em âmbito individual ou coletivo. Ressalta-se que os fatores de exclusão e acesso aos dispositivos tecnológicos decorrem de inúmeras variáveis, que, por vezes, não dependem do indivíduo, sendo este pertencente à estrutura social a qual está vinculado.

Percebe-se que existe uma atenção da CI com as necessidades informacionais dos seres humanos, conforme a noção atemporal de responsabilidade social estabelecida por Wersig e Nevelling (1975), tida como um ideal independente da época histórica em que foi enunciada, os dois autores defendem que "transmitir o conhecimento para aqueles que dele necessitam é uma responsabilidade social, e essa prática parece ser o verdadeiro fundamento da Ciência da Informação" (WERSIG; NEVELING 1975, p. 132). Em 1993, o autor Wersig sugeriu uma rede conceitual a partir do entrelaçamento de conceitos científicos da CI com áreas correlatas e que fossem dadas maior relevância às estratégias de ação, visando relacionar os fundamentos teóricos com as ações empíricas em prol da avaliação e resolução dos problemas decorrentes das necessidades informacionais. Com isso, parte-se da premissa de um dever social da CI para sociedade contemporânea a partir do tear de uma rede na qual diversos conceitos são entrelaçados. Wersig ainda diz ser a CI uma ciência pós-moderna em que existe a preocupação com os seres humanos e seus problemas.

As mudanças na sociedade exigem profissionais e unidades de informação capazes de se relacionarem presencialmente e virtualmente, ofertando serviços e produtos à comunidade elaborados sobre os novos paradigmas de consumo de informação, entendendo que os usuários são cada vez mais exigentes e conectados. Impulsionados pelas mídias sociais e pelas tecnologias contemporâneas, o perfil atual dos usuários de informação e das comunidades está baseado na

\footnotetext{
${ }^{1}<$ http://www.lti.pro.br/>
} 
interação, na troca e na coletividade, demandando dos profissionais da informação novas experiências e formas de lidar com esse cenário hodierno, e, para isso, faz-se necessário recorrer à interdisciplinaridade, fundamento básico da CI.

Nesse processo de inclusão das minorias destaca-se a afirmação dos autores Dias e Pires (2005, p. 13, grifo nosso), quando argumentam que "informação é um fenômeno de comunicação presente em todas as áreas do conhecimento e tem seu valor em função do contexto, do interesse do receptor, do seu grau de competência e domínio sobre aquele assunto". Entende-se com isso o valor que a informação tem para os indivíduos no processo de desenvolvimento da sociedade, como explicitado por Barreto (2005, p. 2)

[...] a informação é qualificada como um instrumento modificador da consciência do indivíduo e da sociedade como um todo. Entre seres humanos deixa de ser uma medida de organização para ser a própria organização em si, quando referencia o indivíduo ao seu passado, as suas perspectivas de futuro e ao seu lugar no presente. O conhecimento, só se realiza se a informação é percebida e aceita como tal e coloca o indivíduo em um estágio melhor dentro do mundo em que sua história individual se desenrola.

Quanto ao termo "informação", Capurro (2003) explicita seu significado no sentido de "conhecimento comunicado", ressaltando que o desenvolvimento das Tecnologias de Informação e Comunicação (TIC) propiciou o surgimento da sociedade da informação. Entende-se que a troca de saberes entre as ciências agrega novos conhecimentos e questões discutidas são maneiras através das quais os pesquisadores desenvolvem suas ideias, na medida em que estudam e buscam novas ações. Quanto a essa questão, Luhmann (2006, p. 95) afirma que "grandes saltos científicos têm origens imanentes e externas. Os avanços na teoria são causados pelos problemas, concepções e premissas contestáveis de teorias preexistentes, bem como por encontros suplementares com a realidade". As interlocuções com áreas afins mantêm o desenvolvimento das teorias científicas, assim também se apoia a CI. Nessa perspectiva, ressalta-se a importância da inclusão social e digital para acesso à informação e desenvolvimento do indivíduo com deficiência. A inclusão pode ser gerada a partir do reconhecimento da potencialidade de cada pessoa ou grupo, as diferenças que existem entre os mesmos podem estar relacionadas à falta de oportunidades. As limitações não anulam os seres humanos, mas estabelecem restrições que podem ser vencidas por meio de contrapartidas. Assim entende-se a importância das ações da Agenda 2030 para todo o planeta, mas principalmente aos cidadãos menos favorecidos, nessa perspectiva o objetivo 10 da Agenda cita:

10.2 Até 2030, empoderar e promover a inclusão social, econômica e política de todos, independentemente da idade, gênero, deficiência, raça, etnia, origem, religião, condição econômica ou outra.

10.3 Garantir a igualdade de oportunidades e reduzir as desigualdades de resultados, inclusive por meio da eliminação de leis, políticas e práticas discriminatórias e da promoção de legislação, políticas e ações adequadas a este respeito. (ONUBR, 2019)

Tais objetivos visam o desenvolvimento social de pessoas vulneráveis, reduzindo e /ou extinguindo obstáculos que impeçam a concretização da igualdade de oportunidades, neste trabalho ressalta-se a pessoa com deficiência visual e o direito ao acesso amplo a informação de seu interesse. As ações devem ser exercidas em coletividade, quanto mais indivíduos envolvidos mais chances de alcançar resultados. Assim as tecnologias intelectuais são grandes aliadas para a realização de práticas e ganhos compartilhados com eficiência. 


\subsection{O ciberespaço e as tecnologias intelectuais}

A interação entre as tecnologias e os indivíduos se dá num compartilhamento de serviços e num processo em que ambos trocam contribuições e inovações que proporcionam avanço tecnológico à humanidade. Conforme Lévy $(1999$, p. 36) discute a existência de uma dimensão social denominada ciberespaço no qual denomina como, "novo meio de comunicação que surge da interconexão mundial de computadores [...] não apenas a infraestrutura material da comunicação digital, mas também o universo oceânico de informações que ela abriga [...]”. O surgimento das tecnologias de informação e comunicação possibilita a produção, compartilhamento e transferência da informação não apenas física, mas virtualmente e em tempo real.

Os indivíduos devem ter competências para saber acessar e utilizar a informação a partir do conhecimento adquirido e para produzir novos conhecimentos. Desse modo é importante que os usuários tenham a capacidade de discernir sobre a informação, destacando-se assim os padrões de competência em informação propostos pela American Library Association (ALA) (1989): saber quando precisam de informações; ter a capacidade de localizá-las e avaliá-las; também usar de forma eficaz; saber como aprender, porque sabem como a informação é organizada, como encontrála e como usá-la de forma que os outros também aprendam com ela; e estarem preparados para aprendizagem no decorrer da existência.

Em uma sociedade em que as redes e sistemas ocupam um espaço cada vez maior ressalta-se a importância de os indivíduos possuírem autonomia quanto a suas demandas informacionais e às mudanças no modo de produção e utilização do conhecimento propiciado pela informação. Como a informação é o principal objeto de pesquisa da CI são necessárias regras para gerenciar seus produtos e serviços, bem como para recuperação, organização, acesso e utilização da informação o que González de Gómez (2002, p. 34) define como regime de informação:

[...] um modo de produção informacional dominante numa formação social, conforme o qual são definidos sujeitos, instituições, regras e autoridades informacionais, os meios e os recursos preferenciais de informação, os padrões de excelência e os arranjos organizacionais de seu processamento seletivo, seus dispositivos de preservação e distribuição.

$\mathrm{Na}$ ação de informação participam sujeitos culturais, tecnológicos, dispositivos de regulamentação numa rede de serviços e produtos, e o regime de informação atende a uma variedade de demandas informacionais da sociedade, servindo as comunidades atuais e vindouras de maneira a preservar e organizar o conhecimento, bem como torná-lo acessível a todos os indivíduos.

\subsubsection{Acessibilidade para deficientes visuais na internet}

As tecnologias de comunicação e informação são aliadas nas ações de inclusão e acessibilidade, além de proporcionar o desenvolvimento das minorias sociais, que geralmente encontram obstáculos no acesso à informação no cotidiano. A literatura relata que a Declaração Universal dos Direitos Humanos, adotada e proclamada pela Assembleia Geral das Nações Unidas (ONU), em 1948, desde o princípio enfatiza a democracia e liberdade de informação como direitos de todas as pessoas, e isso contribuiu para a acessibilidade informacional. Destarte, "A informação se qualifica como instrumento modificador da consciência do indivíduo e do grupo social, pois sintoniza o homem com a memória de seu passado e com as perspectivas de seu futuro." (BARRETO, 2002, p. 49). 
Nesse contexto, a acessibilidade, significa "remover barreiras que impeçam as pessoas com deficiência de participarem de atividades do cotidiano, incluindo o uso de serviços, produtos e informação [...]" (DIAS, 2007, p. 53). A acessibilidade à informação digital só é possível quando são eliminadas barreiras na comunicação, quando os desenvolvedores de tecnologia digital se preocupam em facilitar o acesso a todas as pessoas, independentemente de sua situação social, econômica, intelectual e cultural, minimizando as dificuldades em operar determinados tipos de dispositivos, criando interfaces - superfícies de contato que refletem as propriedades físicas das partes que interagem - , documentando as funções a serem executadas e o balanço entre poder e controle (ROCHA; BARANAUSKAS, 2003). Assim, vários instrumentos tecnológicos foram e são criados, melhorados, atualizados para condizerem com a realidade da pessoa com deficiência e útil na execução das atividades do cotidiano.

A deficiência visual é classificada em cegueira e baixa visão, de acordo com as definições médicas e educacionais. O órgão da visão trabalha junto ao cérebro na responsabilidade de captar toda e qualquer informação visual, a imagem é formada no cérebro a partir da coleta de luz feita pelos olhos. Deve-se fazer a distinção entre pessoa cega e com baixa visão, pois a maneira de leitura muda, também difere a forma de ensino e a utilização ou não do Braille. A Fundação Dorina Nowill para Cegos (2018) explica que cegos são indivíduos desprovidos de visão ou com pouca capacidade de ver, levando-os a necessitarem do Sistema Braille. A pessoa com baixa visão ou visão subnormal enxerga até $30 \%$ mesmo depois de tratamento e correções, tem dificuldade em identificar detalhes, veem os objetos com obstáculos, mas conseguem ler textos impressos ampliados ou com uso de recursos óticos especiais.

Observa-se que a pessoa com deficiência visual, para ter acesso às informações disponíveis digitalmente, precisa de recursos do computador, além de habilidade em manuseá-lo bem como os programas. Desse modo, as tecnologias intelectuais são importantes mediadoras para tornarem a informação acessível a esses usuários, e despertar o interesse de empresas em fornecerem serviços adaptados para deficientes. A W3C, um consórcio que reúne organizações interessadas em firmar padrões para conteúdos acessíveis na web, cita em seus documentos:

Acessibilidade na Web é a possibilidade e a condição de alcance, percepção, entendimento e interação para a utilização, a participação e a contribuição, em igualdade de oportunidades, com segurança e autonomia, em sítios e serviços disponíveis na web, por qualquer indivíduo, independentemente de sua capacidade motora, visual, auditiva, intelectual, cultural ou social, a qualquer momento, em qualquer local e em qualquer ambiente físico ou computacional e a partir de qualquer dispositivo de acesso. (WORLD WIDE WEB CONSORTIUM, 2013, p. 24).

É importante oportunizar os indivíduos para a integração na sociedade da informação e afastar barreiras que impeçam a aproximação dos mesmos ao conhecimento, nisto, destacam-se os conceitos de inclusão social voltada para deficientes visuais, para integração dessas pessoas em qualquer espaço, seja físico, seja virtual. Pesquisas e estudos relacionados à deficiência são indispensáveis para discussão acerca da inclusão, que é "[...] o ato ou efeito de incluir; ato pelo qual, um conjunto contém e inclui outro." (FERREIRA, 2009, p. 931). Os indivíduos, sejam deficientes ou não, têm o direito de obter a informação de que necessitam desde que não firam a lei ou regras institucionais, assim deve-se pensar em serviços e produtos para todos os perfis de cidadãos. Considera-se que as tecnologias de informação e comunicação são meios imprescindíveis no desenvolvimento e bem-estar das pessoas, proporcionando oportunidades de participação e compartilhamento na sociedade da informação.

Nesse contexto, ressalta-se a importância da inclusão social e digital para acesso à informação e desenvolvimento do indivíduo/cidadão, independente de seu aspecto físico. A inclusão do deficiente visual é gerada a partir do reconhecimento de sua potencialidade, as diferenças que existem entre os videntes e os não videntes não estão relacionadas à capacidade cognitivas das 
pessoas. Os seres humanos podem possuir limitações referentes a fatores psicológicos, físicos, econômicos e outros, deste modo, a cegueira não inutiliza, mas estabelece restrições físicas que, assim como outras, podem ser vencidas, assim destaca-se a afirmação de Freire (2006, p. 3):

[...] a democratização do acesso às tecnologias digitais de informação e comunicação deveria ser vista como elemento fundamental nas políticas inclusão social, de modo a ajudar as populações economicamente carentes a se beneficiarem das vantagens do progresso tecnológico, reforçando o caráter democrático da sociedade da informação.

Encontram-se uma gama de software criado para auxiliarem nas necessidades informacionais de usuários com deficiência visual e assim modificar a mensagem para informação acessível. Nielsen (2000, p. 302) afirma que "os problemas de acessibilidade mais sérios, dado o atual estado da $w e b$, relacionam-se a usuários cegos e a usuários com outras deficiências visuais, posto que a maioria das páginas da web seja altamente visual". Acredita-se que a responsabilidade social aliada à tecnologia de informação e comunicação permite a inserção da pessoa com deficiência visual na sociedade do conhecimento, mas, para isso, devem existir produtos e serviços que atendam a demandas dos usuários. "Muitas vezes, os clientes deficientes tornam-se clientes fidelíssimos após encontrar fornecedores que lhes oferecem um bom atendimento e satisfazem às suas necessidades especiais". (NIELSEN, 2000, p. 298). Pessoas com deficiência sentem-se satisfeitas ao encontrarem serviços e produtos que atendam suas demandas, entretanto há uma tendência em fabricar instrumentos que acolham a maioria dos grupos, enquanto serviços dirigidos a minorias são sempre mais caros e mais difíceis de serem encontrados no mercado.

Destaca-se a relevância dos portais virtuais para a disseminação da informação e do conhecimento, e nessa ambiência as informações devem estar organizadas de maneira a facilitar o acesso. Para isso, faz-se necessário uma interface amigável que proporcione o uso das ferramentas com eficácia. Assim o conceito de usabilidade, definido pela ISO 9241 (1998, parte 11) é "até onde um produto pode ser usado por usuários específicos para atingir objetivos específicos com eficácia, eficiência e satisfação em um contexto específico de uso". Sendo os portais virtuais um meio de comunicação e acesso à informação têm também por objetivo a interação com seus usuários. Nesse aspecto, vale ressaltar que, com o crescimento de conteúdos na internet, aumenta a dificuldade em se avaliar a condição das informações prestadas, e essa situação é vivida por muitos pesquisadores que buscam informações na web. Por causa da diversidade de conteúdo é necessária uma pesquisa mais apurada, a fim de selecionar informação precisa e de qualidade.

\section{Metodologia}

O método indiciário foi o que impulsionou este trabalho, Ginzburg (1989) chama seu usuário de "caçador", esse investigador tem a perspicácia necessária para o exercício de desvendar situações escondidas e com o mínimo de informações, e então formar juízos de valor. Assim, no início desta investigação, não se sabia quais filtros ou estratégias aplicar (browsing), mas, no desenvolver do trabalho, essas questões foram sendo resolvidas.

Enquanto procedimentos e instrumentos de coleta de dados buscou-se avaliar as páginas da internet com conteúdos para a temática em questão, tais como, sites, mídias sociais, blogs e bases de informação científica. Tais fontes documentais revelaram-se propícias ao objetivo deste trabalho, e por isso, foram eleitas para este estudo. Para Rodrigues (2007), a materialidade do documento não se restringe ao papel, ou seja, um site e/ou blogs é um documento digital. Para Andrade (2010, p. 30 ), "a internet, essa outra forma de pesquisa tornou o acesso muito mais amplo e praticamente sem 
fronteiras físicas". Por isso, o pesquisador precisa ter um perfil "detetive" para investigar pacientemente os resultados obtidos e filtrar o que é pertinente.

Para aplicação das técnicas foram construídas planilhas como instrumentos de coleta de dados com a função de registro das informações referentes aos artigos e trabalhos obtidos em cada base. As planilhas foram compostas das seguintes categorias: título; autores; ano; fonte; periódico; palavras-chave e resumo, assim constituídas dos itens recuperados nas bases, e depois da averiguação do conteúdo, foram excluídos os itens repetidos e sem pertinência. As categorias temáticas favoreceram a obtenção e representação do quantitativo e dos descritores das publicações. Para os conteúdos dos sites e blogs realizou-se um levantamento quanto aos nomes; descrições e endereços eletrônicos.

Quanto à abordagem, utilizou-se a quali-quantitativa, por atender o perfil deste trabalho. Segundo Bufrem (2001), é comum nos círculos acadêmicos a utilização das abordagens qualitativa e quantitativa de modo dicotomizado, porém, a autora ressalta a importância da superação desta dicotomia, pois grande parte do conhecimento produzido utiliza-se das duas abordagens, seja em menor, ou maior escala. Em suma, o enfoque simultâneo, qualitativo e quantitativo, caracteriza complementaridade e concretização possível para pesquisa em informação.

Desse modo, foram utilizados: o método indiciário com o propósito de identificar os primeiros indícios da pesquisa; estudo de natureza aplicada que para Vergara (2013) tem como finalidade a prática e é motivada por uma necessidade imediata ou não; a pesquisa documental para o levantamento das fontes de informação; a técnica de brauseio para guiar a navegação no ciberespaço e criação de planilhas para registros dos dados.

\subsection{Processos metodológicos}

Será descrito o passo a passo da trajetória desta pesquisa e as ferramentas utilizadas. Abaixo, apresentam-se a criação de estratégias, seleção e a sistematização para a busca dos conteúdos.

a) Seleção do motor de busca (blogs): Os blogs são páginas que podem alocar uma grande diversidade de informações, sendo elas pessoais ou coletivas, segmentadas ou gerais. Ao longo do processo de brauseio, identificou-se que existem blogs que atendem especificamente ao grupo implicado e, por isso, foram considerados na pesquisa.

b) Seleção dos artigos da Base de Dados Referenciais de Artigos de Periódicos em Ciência da Informação (Brapci): a escolha da Brapci se fundamenta por tratar-se da maior base de dados brasileira da área de CI, indexando 57 revistas científicas e recuperando quase 20 mil textos publicados. É credenciada como o principal recurso brasileiro de busca de informações científicas da área.

c) Seleção de trabalhos do Encontro Nacional de Pesquisa em Ciência da Informação (Enancib): elegeram-se os trabalhos do Enancib pelo importante resultado que o evento proporciona para a pesquisa na área da CI. O evento reúne pesquisadores organizados em grupos de trabalhos, abrangendo os principais temas de interesse da área. Os trabalhos são armazenados no Benancib ${ }^{2}$ um repositório do Projeto de Pesquisa "Questões em Rede".

d) Seleção dos textos da Biblioteca Digital Brasileira de Teses e Dissertações (BDTD): considerado um importante repositório em que estão contidos os trabalhos completos dos estudantes das instituições de ensino e pesquisa do Brasil, inclusive, das Escolas de Biblioteconomia e da Ciência da Informação, sendo de interesse deste trabalho ${ }^{3}$.

e) Seleção dos artigos da Web of Science (WoS): por ser uma base de dados que cobre $12 \mathrm{mil}$ títulos de periódicos, com acesso à maioria dos conteúdos na íntegra assinados pela

\footnotetext{
${ }^{2}$ Endereço do Benancib: 〈http://repositorios.questoesemrede.uff.br/repositorios/handle/123456789/2>.

${ }^{3}$ Endereço da BDTD: <http://bdtd.ibict.br/vufind/>.
} 
Coordenação de Aperfeiçoamento de Pessoal de Nível Superior (Capes) ${ }^{4}$, além de ter artigos, trabalhos, capítulos de livros e editoriais de várias áreas do conhecimento, inclusive, da CI.

f) Seleção de fontes de informações virtuais: denominamos fontes de informações virtuais os conteúdos encontrados em sites por meio do Google, um buscador que está à disposição de qualquer pessoa com acesso à internet, além de ser um site muito conhecido e utilizado em todo o mundo. Pode-se considerá-lo útil para pesquisa com poucos indícios, já que nos encaminha aos sites específicos, mesmo com o problema da baixa precisão e grande revocação das pesquisas. Buscou-se por: leis e decretos; página do Governo Federal acessível; serviços e produtos para deficientes visuais; distribuição gratuita de livros em Braille, falados e digitais; jogos; Facebook e sites de audiodescrição. Tais itens foram escolhidos a partir do brauseio no Google, nos blogs e na literatura científica. Já a escolha pelos assuntos "ampliadores de tela para usuário com baixa visão", "avaliadores de acessibilidade", "leitores de tela", "software síntese e reconhecimento de voz", foi realizada a partir da literatura, fruto da revisão bibliográfica acerca dos deficientes visuais. Os textos lidos citam tecnologia assistiva e diversos meios de acesso à informação para esse público, com isso, chegou-se aos referidos temas.

g) Criação da estratégia de busca para os blogs: dada a alta tendência à dispersão do mecanismo de busca do Google, criou-se uma estratégia pautada na busca avançada, que proporciona maior precisão à pesquisa. Estabeleceu-se a raiz quadrada $(\sqrt{ } \mathrm{x})$ nos itens encontrados para o recorte. Nisto os resultados equivalem as 10 primeiras páginas das buscas. Tal prática viabilizou a pesquisa e assegurou que apenas as respostas mais relevantes fossem consideradas. Desta feita, as buscas foram realizadas conforme a Tabela 1.

Tabela 1: Estratégia de busca avançada no Google (blogs)

\begin{tabular}{ll}
\multicolumn{1}{c}{ Filtros } & \multicolumn{1}{c}{ Blog } \\
Todas estas palavras: & acessibilidade AND “deficiente visual” AND blog \\
Idioma: & Português \\
Região: & Brasil \\
Última atualização: & no último ano \\
Termos que aparecem: & em qualquer lugar da página \\
SafeSearch: & mostrar resultados mais relevantes \\
Tipo de arquivo: & em qualquer formato \\
Direitos de uso: & não filtrado por licença \\
\hline
\end{tabular}

Fonte: Dados da pesquisa, 2019.

h) Criação de estratégia de busca para Brapci: como estratégias para a identificação dos registros de produção sobre a temática de interesse da presente pesquisa, os termos utilizados foram: "cegos", "deficiente visual", "Braille" e "acessibilidade na web", selecionando a opção de busca por todos os campos e considerando todo o período da base.

i) Criação de estratégia de busca para o Benancib: os termos de busca foram os mesmos utilizados na Brapci. Foi realizada a busca simples, por cada termo. E usado os filtros por todos os campos.

\footnotetext{
${ }^{4}$ Endereço para aceso a WoS: 〈http://www.periodicos.capes.gov.br/>. Dados de fevereiro de 2018.
} 
j) Criação de estratégia de busca para a BDTD: a busca foi realizada no primeiro momento por todos os campos: título, autor e assunto com os mesmos termos citados anteriormente. Usou-se o filtro: "área do conhecimento", e a opção, "Ciências Sociais Aplicadas, Ciência da Informação".

k) Criação de estratégia de busca para a WoS: os descritores utilizados na pesquisa foram "blind", "visually impaired", "Braille" e "web accessibility". A área de pesquisa selecionada foi Information Science and library Science e o acesso à base se deu pelo Portal de Periódicos da Capes, utilizando a rede da Comunidade Acadêmica Federada (CAFe).

l) Criação de estratégias de busca para fontes de informações virtuais: buscou-se no Google avançado pelos seguintes termos: "ampliadores de tela" AND "baixa visão"; "avaliador de acessibilidade"; "leitor de tela" AND "deficiente visual"; "síntese de voz" AND "reconhecimento de voz"; "serviços" AND "produtos" AND "deficiente visual"; "livros gratuitos" AND "deficiente visual"; "jogo" AND "deficiente visual”, seguindo os mesmos filtros utilizados para os blogs.

Essas fontes de informações virtuais foram mais trabalhosas, dada a grande revocação de resultados, e ao fato de se tratar de termos compostos, dando margem a uma dispersão maior nos resultados. Por isso, recorreu-se a indícios na busca a partir da literatura para nortear a investigação de modo mais preciso, e evitando perda de tempo com páginas que não eram pertinentes. As buscas por Leis e Decretos foram feitas no Portal da Legislação 5 no link "Pesquisa de Legislação". Na opção simples, pesquisou-se pelos termos "cego", "deficiente visual", "Braille" e, dessa vez, por "acessibilidade", visto que "acessibilidade na web" não retornou nenhum resultado. Marcou-se a opção, "Exato", que fica abaixo da opção "Termos". No "Tipo de Ato", foi acrescido "LEI - Lei ordinária" e/ou "DEC - Decreto Executivo".

A pesquisa para as páginas do Governo Federal foram resultados a partir da busca dos blogs que muitas vezes citavam sites do governo e sua acessibilidade. A partir disso, foi feita a busca no site do Governo Federal ${ }^{6}$, encontrando os endereços dos Ministérios em que todos possuem o link acessibilidade.

Quanto às redes sociais percebeu-se nas pesquisas que os blogs a maioria possui perfil no Facebook. Nesta página pesquisou-se por cada termo, utilizando o filtro "Categoria: Empresa, organização ou instituições". Foram contabilizados os 100 primeiros resultados de cada descritor, a partir desse quantitativo, os perfis eram páginas vazias e algumas os termos eram usados em outros sentidos.

\section{Apresentação dos resultados}

Durante a pesquisa nas bases foram encontrados muitos trabalhos repetidos e na busca no Google, foram localizados itens sem pertinência alguma ao tema e muitos anúncios (ambos retirados na análise). Nesse contexto, percebeu-se que o termo "cego" foi o que mais recuperou itens fora da temática em todas as fontes de informação. Muitos artigos foram recuperados, porque tinham em alguma parte do texto as expressões: "ponto cego", "avaliação cega" e também trabalhos sobre assuntos bibliométricos que citavam títulos de artigos com alguns dos termos de busca.

Percebeu-se na pesquisa feita nos blogs que a maioria é sobre deficiência em geral. Quanto à deficiência visual, a quantidade diminui substancialmente, o que pode significar que os conteúdos sobre a temática são encontrados juntos a outras deficiências, em páginas que contemplam a deficiência como um todo. Desse modo, observaram-se indícios de desinteresse nas publicações

\footnotetext{
${ }^{5}$ Endereço do Portal: 〈http://www4.planalto.gov.br/legislacao〉.

${ }^{6}$ Disponível em: <http://www.brasil.gov.br/>
} 
específicas sobre deficiência visual na internet, pois, a especificidade pode reduzir o número de usuários interessados, por isso, páginas que contemplam múltiplas deficiências são mais comuns.

Buscou-se dar uma atenção especial neste trabalho aos blogs, tendo em vista o espaço restrito para a divulgação detalhada dos demais resultados e a importância destas tecnologias para o diálogo direto com o público deficiente na web, reconhecendo, que, inclusive, estas páginas frequentemente são administradas por deficientes visuais que operam a produção de conteúdo, participando ativamente dos processos de disseminação da informação no ciberespaço. Com isto, constataram-se 77 blogs, sendo que apenas 19 têm relação direta com deficiência visual, sendo que, apenas 4 são específicos no tema, os outros 15 tratam de deficiências em geral, inclusive, a visual. Sobre a presença dos blogs em redes sociais, verificou-se que todos os identificados na pesquisa estão presentes em, pelo menos, uma rede. A figura 1 sistematiza as redes sociais mais utilizadas pelos blogs que compõem o corpus da pesquisa. O grafo foi construído através da ferramenta UCINET, sendo que os pontos em vermelho indicam as redes sociais, e os na cor azul, os blogs.

Figura 1: Grafo de relação entre os blogs e as suas respectivas redes sociais

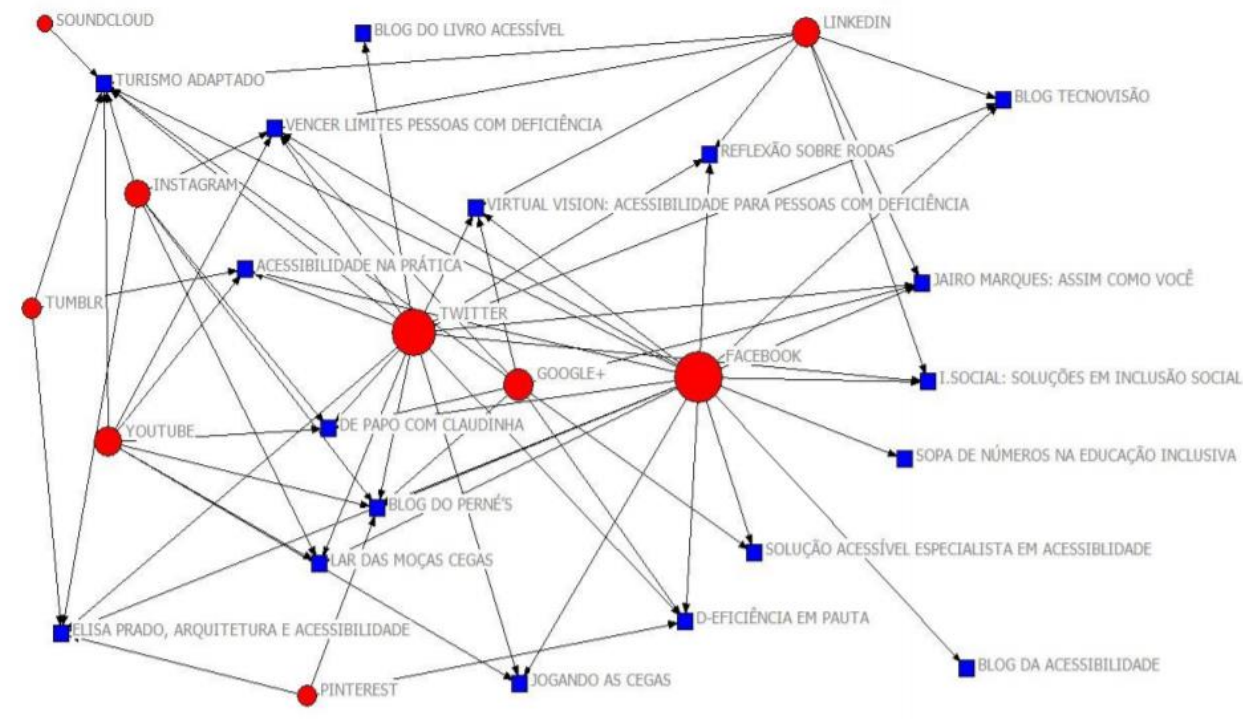

Fonte: Dados da pesquisa (2019).

Ainda sobre a figura 1, nota-se que o Facebook (17 blogs) é a rede social mais utilizada. Além dele, as principais redes em ordem de frequência, são: Twitter (15), Google+ (8), YouTube (7) e LinkedIn (7). Em suma, segundo a Figura 1, os blogs que possuem mais redes sociais são os seguintes: Turismo Adaptado (8), blog do Perné's (6), Vencer Limites Pessoas com Deficiência (6), De Papo com Claudinha (5) e Elisa Prado, Arquitetura e Acessibilidade (5).

$\mathrm{Na}$ Brapci, há maior disponibilidade de artigos relacionados a estudos de caso, tecnologias, educação e outros assuntos. Na BDTD, foram localizadas cinco dissertações e nenhuma tese, pois, muitos textos tratavam de outras deficiências. O Benancib, repositório que armazena toda a coleção de artigos do Enancib recuperou trabalhos relevantes que tratam de diversos assuntos dentro da CI. $\mathrm{Na}$ WOS, a temática é bem coberta, articulando o tema com questões de tecnologia, inovação e sistemas de navegação. No Facebook, foi encontrada uma quantidade considerável de páginas, mas muitas desatualizadas, e o termo "cego" também teve inconsistência como o perfil "o amor é cego", cuja expressão está em outro sentido.

De modo geral, foram recuperados 57 documentos na Brapci, tendo o Prof. Marckson Roberto Ferreira de Sousa (UFPB) como o pesquisador mais produtivo, com 4 publicações. Para 
complementar a compreensão do estudo a partir das frequências temáticas identificadas na produção científica, utilizamos a técnica de nuvem de tags. Assim foi possível ordenar as palavras-chave por frequência absoluta e compreender os temas mais explorados pelos pesquisadores da área de CI. O instrumento de elaboração das nuvens utilizado foi à tecnologia Wordle ${ }^{7}$. Em resumo, constatou-se que os termos mais frequentes foram: deficiente visual (13), acessibilidade (11), ciência da informação (10), biblioteconomia (8), deficiência visual (8), biblioteca para cego (5) e Braille (5).

Figura 2: Nuvem de tags das palavras-chave recuperadas na Brapci

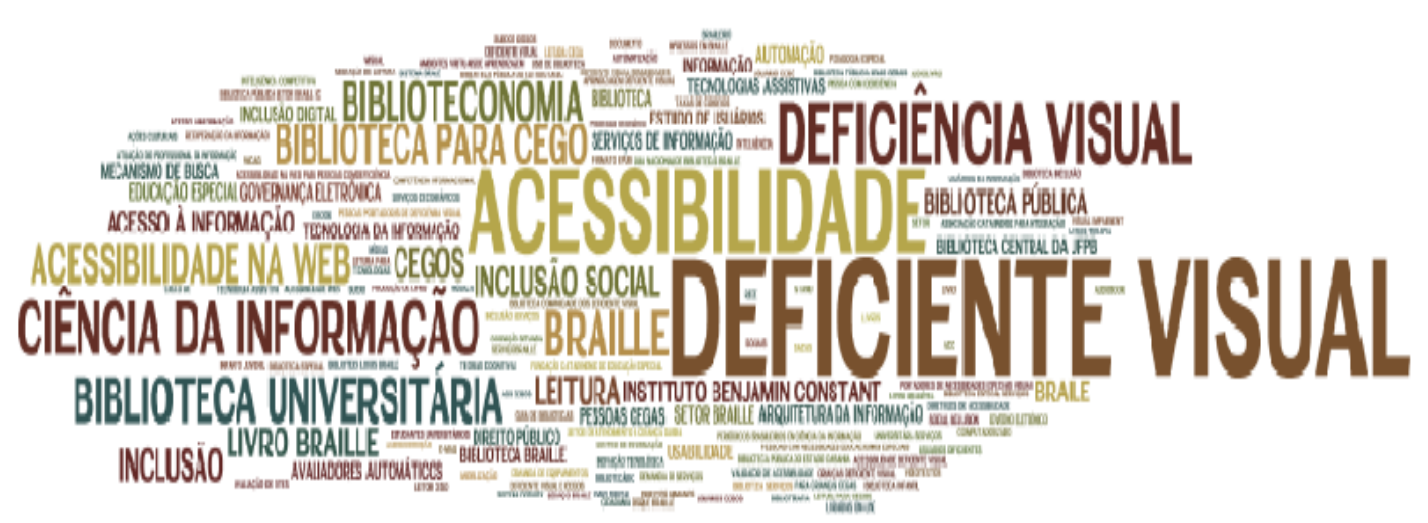

Fonte: Dados da pesquisa (2019).

Tal resultado expressa a forte ênfase dos estudos nas questões vinculadas à acessibilidade em bibliotecas para deficientes visuais, no contexto da Biblioteconomia e da Ciência da Informação. Muitos artigos destacam o histórico do deficiente visual e estudos de caso de bibliotecas acessíveis.

$\mathrm{Na}$ WoS foram recuperados 29 textos, tendo como destaques os periódicos científicos: Revista española de Documentación Científica (4) e El profesional de la información (4). Na Figura 3, vê-se uma nuvem de tags representando as palavras-chave mais indexadas nos artigos da WoS.

Figura 3: Nuvem de tags das palavras-chave recuperadas na WoS

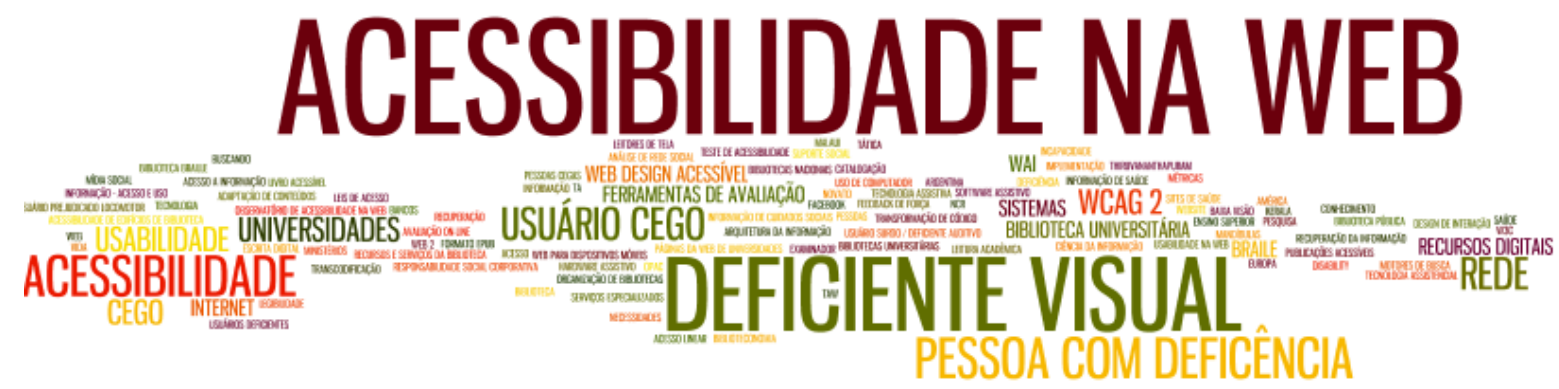

Fonte: Dados da pesquisa (2019).

7 Disponível em: 〈http://www.wordle.net/create〉. 
Assim, o termo "acessibilidade na web" em destaque é o mais representativo com 14 ocorrências, depois "deficiente visual" com 8, não necessariamente porque se procurou por ele, pois também se buscou por "cego" e "Braille", que foram vistos com destaque menor. O termo "acessibilidade" teve cinco ocorrências; "usuário cego" e "rede", quatro. Percebe-se que a temática "deficiência visual" é trabalhada articulada a assuntos de tecnologias, inovações e sistemas de navegações.

No Benancib, 31 trabalhos foram identificados, tendo a professora Sandra Albuquerque Siebra (UFPE), com 6 produções, como a mais representativa.

O ano de 2015 foi o que mais se destacou em produções no Benancib (nove publicações) e WoS (seis publicações). Nesse ano, instituiu-se o Estatuto da Pessoa com Deficiência, a Lei n. ${ }^{\circ}$ 13.146, de 6 de julho de 2015. Representa um avanço da sociedade para inclusão e acessibilidade de minorias que por anos viveram sem direito à educação e sem o mínimo para um ser humano sobreviver.

No Benancib, as palavras-chave em destaque foram: "acessibilidade" com 12 ocorrências, "deficiente visual" com 7, "acessibilidade na web" com 6, "acesso à informação" com 5, universidades com 4, lei de acesso com 4. Pode-se perceber uma variedade de descritores relacionados à deficiência visual, a Figura 4 mostra uma série de termos que foram citados nos artigos relacionados à temática.

Figura 4: Nuvem de tags das palavras-chave recuperadas na Benancib

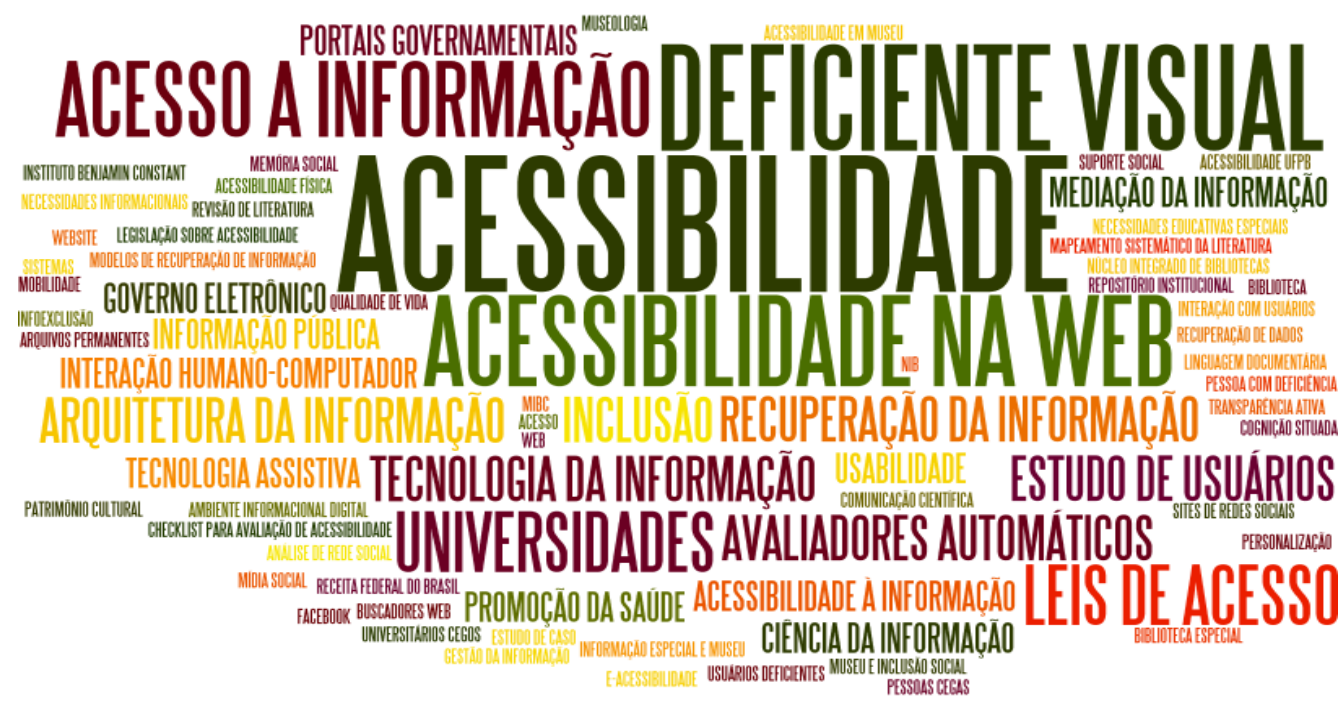

Fonte: Dados da pesquisa (2019).

$\mathrm{Na}$ BDTD, apenas 5 dissertações foram localizadas, ressalta-se que todas as produções científicas mencionadas são restritas à CI. Esse resultado se deu na medida em que os filtros foram sendo aplicados, mesmo sem recorte temporal ao filtrar pela área do conhecimento, "Ciência da Informação", a pesquisa mostra 14 itens dos quais 9 não são pertinentes, pois tratam de outras deficiências. Outros citam os termos "às cegas" e "ponto cego" e trabalhos sobre análise de produção científica que mencionam artigos desse tema.

Logo mais na Figura 5, os termos que se destacaram na pesquisa na BDTD foram: deficiente visual (três ocorrências) e Ciência da Informação (duas ocorrências). Os demais descritores foram citados uma vez, sendo distribuídos nas dissertações. 
Figura 5: Nuvem de tags das palavras-chave recuperadas na BDTD

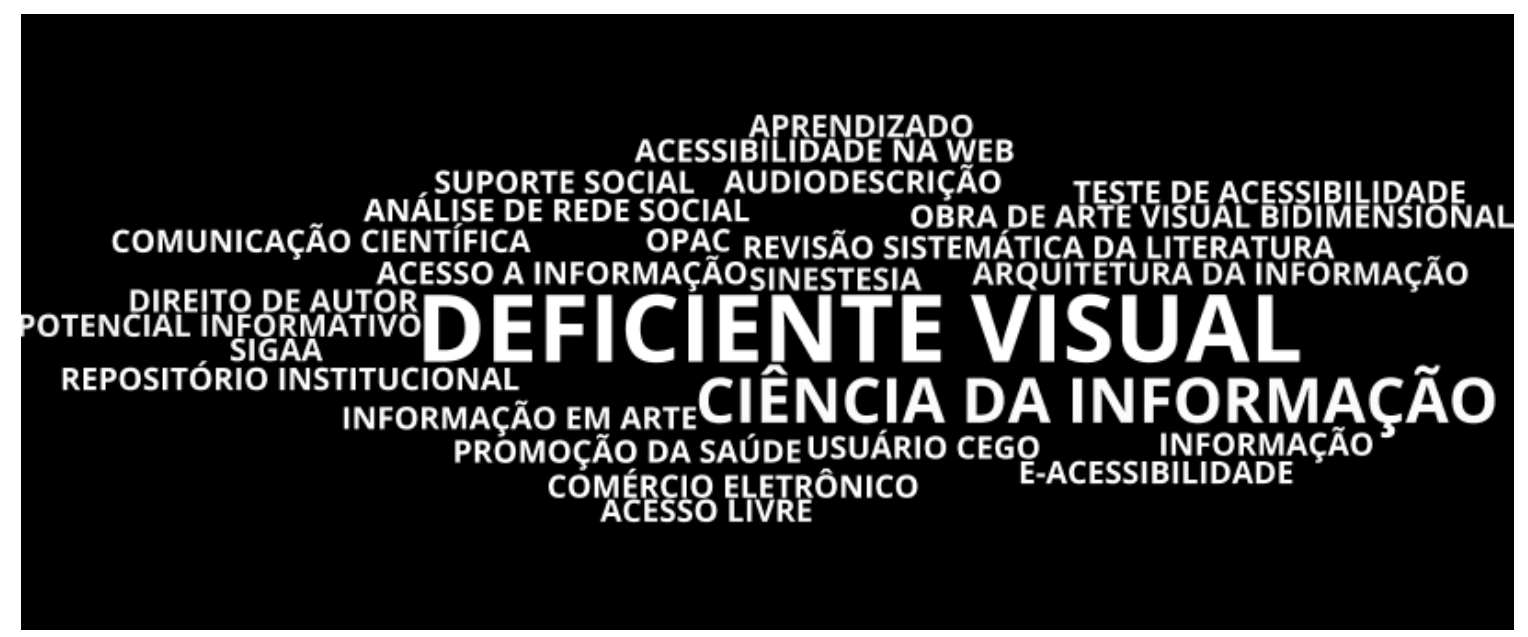

Fonte: Dados da pesquisa (2019).

No mais, encontraram-se 13 leis e 13 decretos, 22 páginas do governo federal acessíveis, 4 jogos, 3 sites de distribuição de livros gratuitos, 4 sites de audiodescrição, 6 serviços e produtos, 18 softwares de síntese de voz, 7 ampliadores de tela, 4 avaliadores de acessibilidade, 6 leitores de tela e 186 perfis do Facebook.

\subsection{Desenho da proposta para a página LTi $D V$}

Com base nas categorias utilizadas, chegou-se à seguinte proposta de organização dos conteúdos para a Página LTi DV, no Portal LTi:

\section{> INFORMAÇÃO PARA DEFICIENTES}

- Ampliadores de tela para usuário com baixa visão

- Avaliadores de acessibilidade

- Leitores de tela

- Páginas do Governo Federal acessíveis

- Sites de audiodescrição

- Software síntese e reconhecimento de voz

\section{INFORMAÇÃO PARA DEFICIENTES E PROFISSIONAIS DA INFORMAÇÃO}

- Brapci

- WoS

- ENANCIB

- BDTD

\section{$>$ UTILIDADE PÚBLICA}

- Leis e decretos

- Serviços e produtos para deficientes visuais 


\section{OBJETOS DE INFORMAÇÃO}

- Distribuição gratuita de livros em braille, falados e digitais

\section{ESPAÇOS DE COMUNICAÇÃO}

- Blogs

- Rede social - Facebook

\section{LAZER}

- Jogos

$\mathrm{Na}$ distribuição dos conteúdos apresentados acima, os títulos em caixa alta se referem aos temas gerais que remetem as fontes de informações encontradas na internet. Assim, pretende-se buscar um número expressivo de informações com qualidade e pertinência, para alimentar a página LTi $\boldsymbol{D} \boldsymbol{V}$, disponibilizando os materiais por categorias.

\section{Considerações finais}

A proposta LTi $\boldsymbol{D} \boldsymbol{V}$ é estimular o conhecimento sobre a temática, fomentar o processo de inserção sociodigital, propiciar a competência nas buscas pela informação, possibilitando uma aprendizagem ampliada e compartilhadas. Também, manter o compromisso do Portal com a sociedade do conhecimento em disponibilizar informação, sendo ainda um espaço de informações para pessoas com deficiência visual e para profissionais da informação interessados na temática.

As mudanças na sociedade exigem profissionais e unidades de informação capazes de se relacionarem presencialmente e virtualmente, ofertando serviços e produtos à comunidade elaborados sobre os novos paradigmas de consumo de informação, entendendo que os usuários são cada vez mais exigentes e conectados.

Impulsionados pelas mídias sociais e pelas tecnologias contemporâneas, o perfil atual dos usuários de informação e das comunidades está baseado na interação, na troca e na coletividade, demandando novas experiências e formas de lidar com esse cenário hodierno. Destaca-se a importância de produzir conteúdos sobre o tema na área da CI, pois ressalta o compromisso com a sociedade, as minorias e prevalece à disseminação da informação com equidade. A Agenda 2030 enaltece a colaboração de todos pra alcance pleno dos objetivos propostos, nesse quesito ressalta-se o papel do profissional da informação de fornecer, orientar e facilitar o acesso ao conhecimento, como mediador entre a informação e o usuário, reduzindo a desigualdade informacional e participando na concretização destas ações.

Nesse contexto, ressalta-se a importância da inclusão social e digital para acesso à informação e desenvolvimento do indivíduo/cidadão, independente de seu aspecto físico. A inclusão do deficiente visual é gerada a partir do reconhecimento de sua potencialidade. Nessa perspectiva, destaca-se a relevância dos portais virtuais para a disseminação da informação e do conhecimento, e nessa ambiência as informações devem estar organizadas de maneira a facilitar o acesso. Contudo, este estudo propôs ao Portal LTi a construção de uma página para acesso a fontes de informação de interesse para pessoas com deficiência visual e profissionais da informação.

Nesse aspecto, Freire (2016) diz acreditar que, na Era do Conhecimento, o profissional da informação tem a função de mediador, aproximando produtos e usuários, aproveitando todas as possibilidades existentes na interação emissor/receptor, sendo que, o destinatário escolherá a informação que fará parte das suas atitudes. 


\section{Referências}

American Library Association (ALA). (1989). Presidential Committee on Information Literacy. Chicago: Final Report, Recuperado em 08 de março, 2018, de http://www.ala.org/acrl/publications/whitepapers/presidential.

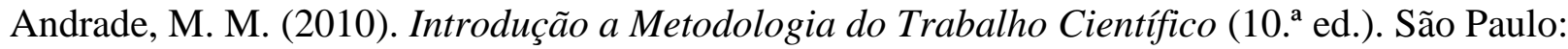
Atlas. p. 117.

Barreto, A. A. (2005, Junho). A estrutura do texto e a transferência da informação.

DataGramaZero. 6(3). Recuperado em 22 de Abril, 2018, de partir do conceito de regime de informação. (Tese de Doutorado em Ciência da Informação, Universidade Federal da Paraíba, João Pessoa, PB).

Lei $\mathrm{n}^{\circ}$ 13.146, de 6 de Julho de 2015 (2015). Institui a Lei Brasileira de Inclusão da Pessoa com Deficiência (Estatuto das Pessoas com Deficiência). Brasília, DF, Recuperado em 28 de setembro, 2018, de http://www.planalto.gov.br/ccivil_03/_Ato20152018/2015/Lei/L13146.htm.

Bufrem, L. S. (2001) Complementariedade qualitativo-quantitativa na pesquisa em informação. Transinformação, Campinas, 13(1), 49-55.

Capurro, R., \& Hjorland, B. (2013) O conceito de informação. Recuperado em 31 de março, 2018, de http://portaldeperiodicos.eci.ufmg.br/index.php/pci/article/view/54/47.

Declaração Universal dos Direitos Humanos: Adotada e proclamada pela resolução 217 A (III) da Assembleia Geral das Nações Unidas em (1948, 10 de dezembro). Recuperado em 26 de março, 2018, de http://unesdoc.unesco.org/images/0013/001394/139423por.pdf.

Dias, C. (2007) Usabilidade na WEB: criando portais mais acessíveis. Rio de Janeiro: Alta Books, p. 296.

Dias, M. M. K., \& Pires, D.(2005) Fontes de informação: um manual para cursos de graduação em Biblioteconomia e ciência da informação. São Carlos: EDUFSCAR, p. 13.

Ferreira, A. B. de H., \& Ferreira, M. B. (Coord.) (2009) Novo dicionário Aurélio da língua portuguesa (4. ed.). Rio de Janeiro: Nova Fronteira.

Freire, I. M. (2006, maio/ago.) Acesso à informação e identidade cultural: entre o global e o local. Ci. Inf., Brasília, 35 (2), 58-67.

Freire, I. M. (2016). Ciência, conhecimento, profissionais da informação. Recuperado em 08 de janeiro, 2019, de http://www.isafreire.pro.br/Inforesponsabilidade_social.htm.

Freire, I. M., Lima, A. P. L., \& Costa, M. P,. Jr. (2012) Mídias sociais na web: De olho na CI para capacitação acadêmica e profissional. Biblionline (vol. 8, n.esp., pp. 175-184). Recuperado em 28 de janeiro, 2019, de http://periodicos.ufpb.br/ojs2/index.php/biblio/article/view/14202/8108. 
Ginzburg, C. (1989). Sinais: raízes de um paradigma indiciário. In: Mitos, emblemas, sinais: morfologia e história (Trans. Federico Carotti. 2. reimp.) São Paulo: Companhia das Letras, p. 143-179.

González de Gómez, M. N. (2003, janeiro/abril) As relações entre ciência, estado e sociedade: um domínio de visibilidade para as questões da informação. Ciência da Informação 32(1), 60-76.

ISO 9241. Guidelines on usability (1998). Part 11. In: Ergonimic requeriments for office work with visual display terminals. Recuperado em 05 de março, 2018, de https://www.userfocus.co.uk/resources/iso9241/part11.html.

Lévy, P. (2004). As tecnologias da inteligência: o futuro do pensamento na era da informática. Rio de Janeiro: Editora 34, 203 p.

Lévy, P. (1999). Cibercultura. São Paulo: Ed. 34, 260 p.

Luhmann, N. (2006) A improbabilidade da comunicação (Tradução de Anabela Carvalho) Lisboa: Veja limitada, $154 \mathrm{p}$.

Murray, G. (1999) The portal is the desktop. California: Intraspect.

Nações Unidas no Brasil (ONUBR) (2015, Setembro). Agenda 2030. Recuperado em 11 de março, de 2019, de https://nacoesunidas.org/pos2015/agenda2030/.

Nielsen, J. (2000) Projetando Websites. Rio de Janeiro: ELSEVIER, p. 432.

Rocha, H. V. da; baranauskas, M. C. C. (2003) Design e avaliação de interfaces humanocomputador. Campina: NIED/ UniCamp, 257 p.

Rodrigues, R. M. (2007). Pesquisa acadêmica: como facilitar o processo de preparação de suas etapas. São Paulo: Atlas, 2007. p. 45.

Vegara, S. C. (2013) Projetos e Relatórios de Pesquisa em Administração (12. ed.). São Paulo: Atlas.

Wersig, G., \& Neveling, U. (1975). The phenomena of interest to information science. The Information Scientist (vol. 9, n. 4).

World Wide Web Consortium (W3C) (2013) Cartilha de Acessibilidade na Web. Recuperado em 11 de novembro, 2018, de http://www.w3c.br/pub/Materiais/PublicacoesW3C/cartilha-w3cbracessibilidade-web-fasciculo-I.html. 